\title{
Uma revisão bibliográfica sobre as altas habilidades/superdotação com enfoque na matemática
}

\begin{abstract}
RESUMO
As pesquisas no campo das Altas Habilidades/Superdotação (AH/SD) têm se destacado nas últimas décadas com o propósito de contribuir com a educação especial na perspectiva da educação inclusiva. A partir de consultas à Biblioteca Digital Brasileira de Teses e Dissertações (BDTD), ao Banco de Teses da Capes e aos repositórios de universidades brasileiras (UnB, UFSCar, UNESP, PUCRS, PUCSP, UNIFESP, UFSC, UFPR, UFSM, UFRGS e UFES), o objetivo deste artigo é apresentar uma revisão bibliográfica das pesquisas realizadas, buscando agrupá-las em áreas afins para delinear os principais focos dos estudos implementados com atenção especial às AH/SD em Matemática. As buscas realizadas, entre os anos de 2014 a 2017, utilizaram descritores como Altas Habilidades e Superdotação; as fases da análise do conteúdo se deram por leituras flutuantes e núcleos de significação. Os resultados revelam que as categorias mais exploradas no Brasil são de representação social, identificação e inclusão. Após a expansão das buscas para o contexto mundial, as bases consultadas revelaram que são escassas as pesquisas na área das Altas Habilidades/Superdotação em Matemática, apontando, assim, para a necessidade de estudos relativos a metodologias de ensino e programas de enriquecimento para atender as necessidades educacionais especiais e garantir a efetiva inclusão dos alunos com AH/SD em Matemática.
\end{abstract}

PALAVRAS-CHAVE: Altas habilidades/superdotação. Altas habilidades/superdotação em Matemática. Educação inclusiva. 


\section{INTRODUÇÃO}

A Política Nacional de Educação Especial na perspectiva da Educação Inclusiva trouxe novas concepções à atuação da Educação Especial nos sistemas de ensino brasileiros. O propósito da educação especial se volta atualmente à tarefa de complementar a formação dos alunos que constituem seu público-alvo, por meio do ensino de conteúdos e da utilização de recursos que lhes conferem a possibilidade de acesso, permanência e participação nas turmas comuns de ensino regular, com autonomia e independência, assegurando a inclusão escolar de alunos com deficiência, transtorno do espectro autista e Altas Habilidades/Superdotação (AH/SD) (BRASIL, 2008).

A área das AH/SD no Brasil é relativamente nova e vem ganhando destaque nas últimas décadas. Algumas instituições de ensino vêm desenvolvendo pesquisas sobre esta temática que apresenta um vasto campo a ser explorado.

As AH/SD são definidas como a "interação entre três grupamentos básicos de traços humanos - sendo esses grupamentos as capacidades gerais acima da média, os elevados níveis de comprometimento com a tarefa e os elevados níveis de criatividade" (RENZULLI, 1978, p. 180). Essa concepção serve também como base para a definição do Ministério de Educação do Brasil (BRASIL, 1995), que a adotou nas "Diretrizes gerais para o atendimento educacional aos alunos portadores de Altas Habilidades/Superdotação e talentos".

Nesse sentido, o objetivo do presente estudo é apresentar uma revisão bibliográfica das pesquisas realizadas no Brasil e no contexto mundial para, então, analisarmos como se distribuem essas pesquisas e quais as categorias mais exploradas. Pretendemos, ainda, verificar os avanços acerca das AH/SD em Matemática, buscando conhecer melhor as especificidades desse grupo e as metodologias de ensino que atendam às necessidades educacionais especiais desses alunos.

A partir desse detalhamento, buscamos verificar de que forma as pesquisas têm contribuído para a formação de professores, a identificação das AH/SD em Matemática, para a criação e implementação de metodologias de ensino, de programas de enriquecimento e outros aspectos relevantes para a área.

\section{PROCEDIMENTOS METODOLÓGICOS}

Os primeiros trabalhos produzidos no Brasil na área das AH/SD datam da década de 1920. No entanto, como relatam Pérez e Freitas (2009), a produção científica relativa à área era incipiente no contexto brasileiro. De acordo com as autoras, entre 1971 e 2008, ocorreram apenas 55 eventos técnico-científicos no país, fruto do esforço pela busca de parcerias das associações representativas junto aos órgãos educacionais e instituições de ensino superior e/ou da iniciativa privada.

As publicações científicas sobre o tema, nesse período, também não são numerosas, o que se comprova por meio do estudo de Pérez e Freitas (2009) que investigaram a produção científica registrada pelas universidades brasileiras no Banco de Teses da Capes, entre os anos de 1987 a 2007 e Anjos (2011), que buscou identificar o perfil epistemológico e as tendências da investigação das dissertações 
e teses com a temática "altas habilidades/superdotação/talento", defendidas nos programas de pós-graduação, no Brasil, no período de 1987 a 2009.

Nossa busca por pesquisas relativas ao tema, no Brasil, foi baseada nesses dois trabalhos e complementada até 2017, por meio do Banco de Teses da Capes, por ser considerado um dos mais representativos no âmbito das dissertações e teses nacionais. A facilidade de acesso em meio digital e a disponibilidade dos documentos na íntegra o tornam um campo favorável para a pesquisa bibliográfica. Realizamos buscas também nos repositórios das universidades brasileiras que se destacam pelas pesquisas com AH/SD (UnB, UFSCar, UNESP, PUCRS, PUCSP, UNIFESP, UFSC, UFPR, UFSM, UFRGS e UFES), na Biblioteca Digital Brasileira de Teses e Dissertações do Instituto Brasileiro de Informação em Ciência e Tecnologia (IBICT) As buscas foram realizadas no período de 2014 a 2017, utilizando descritores como Altas Habilidades e Superdotação. Foram adotados procedimentos de análise que iniciaram com a leitura flutuante e, em seguida, os resultados foram agrupados em categorias de significação. Segundo Aguiar e Ozella (2006), as leituras flutuantes permitem destacar e organizar os préindicadores para a construção dos núcleos futuros. "Um critério básico para filtrar esses pré-indicadores é verificar sua importância para a compreensão do objetivo da investigação" (AGUIAR; OZELLA, 2006, p. 22). A partir da releitura do material, iniciamos um processo de articulação que resultou na organização dos núcleos de significação por meio de sua nomeação em categorias. A organização dos núcleos de significação tem como critério a articulação de conteúdos semelhantes, complementares ou contraditórios (AGUIAR; OZELLA, 2006).

Dessa forma, todos os registros encontrados, nos bancos consultados por meio da busca Altas Habilidades e Superdotação, foram agrupados em núcleos de significação, aqui mencionados como categorias. A partir dessa classificação, torna-se mais fácil a compreensão das áreas mais exploradas em detrimento de outras, que permanecem como vasto campo ainda a ser investigado.

\section{RESULTADOS E DISCUSSÕES}

\section{Bases nacionais consultadas}

Registros relativos às $\mathrm{AH} / \mathrm{SD}$ encontrados nos bancos nacionais consultados foram catalogados segundo as categorias apresentadas na Tabela 1, com a finalidade de demonstrar quantitativamente as pesquisas nas principais categorias exploradas.

Tabela 1 - Classificação por categorias das pesquisas sobre Altas Habilidades/Superdotação

\begin{tabular}{|c|c|}
\hline Categorias & $\begin{array}{l}\text { № de } \\
\text { pesquisas }\end{array}$ \\
\hline $\begin{array}{l}\text { 1) Altas habilidades/superdotação associadas a outras necessidades } \\
\text { educacionais }\end{array}$ & 13 \\
\hline 2) Altas habilidades/superdotação em matemática & 6 \\
\hline 3) Atendimento educacional especializado (AEE) & 38 \\
\hline 4) Estudos comparativos "superdotados" e "não superdotados" & 6 \\
\hline 5) Formação docente & 20 \\
\hline
\end{tabular}


6) Representação social: percepção e autopercepção

7) Identificação

8) Inclusão

9) Levantamento bibliográfico

10) Políticas públicas

11) Psicologia: aspectos subjetivos

Fonte: Elaborada pelas autoras (2018)

A partir do total de 272 trabalhos encontrados e das categorias definidas conforme Tabela 1, foi possível observarmos como estão distribuídas as pesquisas brasileiras relacionadas às AH/SD. Assim, a representação social: percepção e autopercepção é a categoria que lidera o ranking das pesquisas brasileiras. Pesquisas como as de Barreto (2008), Manso (2012), Cianca (2012), Romanowski (2013), Araujo (2014), Antonioli (2015) e Santos (2015a) buscam analisar as diferentes percepções dos profissionais da educação acerca dos indivíduos com AH/SD. Dentre as representações mais recorrentes, destacam-se estudantes inteligentes, espertos, curiosos e questionadores; no entanto, muitas falas revelam ideias do senso comum e que ainda persistem muitos mitos acerca das AH/SD, alertando, assim, para a falta de formação docente nessa área.

Por outro lado, temos pesquisas que trazem uma análise da construção do autoconceito e da autopercepção de alunos identificados com AH/SD. A pesquisa de Baptista (2016) aponta para os benefícios da identificação e do encaminhamento para orientação e possibilidades de intervenção e atendimento especializado para os sujeitos com AH/SD, levando-os a uma nova perspectiva de vida e construção de identidade. Os resultados da pesquisa de Correia (2011) alertam para as dificuldades de adaptação escolar e de socialização que ocorrem desde o início da vida acadêmica, causando prejuízos no processo de construção do autoconceito. Foram registradas significativas influências negativas do contexto inadequado das escolas.

Em Trancoso (2011) são observados autoestima altamente elevada e fortes crenças de sucesso acadêmico. $O$ grupo de alunos com AH/SD se percebe e pode ser considerado como habilidoso socialmente e considera as expectativas dos pais, professores e colegas em relação a si como positivas e desafiadoras. Dessa forma, a categoria da representação social dos indivíduos com AH/SD quando abrange a percepção dos profissionais da educação, a percepção dos pais e familiares, a autopercepção e o autoconceito, esclarecem ideias acerca das características dessa população para melhor compreensão desse grupo social. $\mathrm{O}$ autoconceito e a percepção da sociedade mostram como alguns mitos têm gerado expectativas sobre esse público sem reconhecer suas necessidades educacionais. Os estudos têm apontado que, apesar de pertencerem a um grupo social que os reconhece com habilidades superiores em determinadas áreas, alunos com AH/SD apresentam comportamentos e características bastante heterogêneos entre si, chamando a atenção, portanto, para os atendimentos educacionais especializados de acordo com as necessidades educacionais de cada aluno.

Outra categoria amplamente explorada em relação às AH/SD trata da importância da inclusão desse grupo. Inúmeros são os trabalhos que defendem a 
ideia da inclusão dos alunos com AH/SD em salas de aula regulares, reconhecendo, entretanto, a importância de programas que atendam suas necessidades educacionais para que, assim, esses alunos sejam devidamente assistidos. Em seu estudo, Pereira (2008) teve como objetivo investigar as concepções de inclusão de alunos com altas habilidades/superdotação em classes regulares; a percepção de sua inclusão por serem alunos superdotados; as distinções entre as ações pedagógicas de professores de ensino regular em relação ao aluno superdotado e aos demais alunos; e os elementos facilitadores e dificultadores relacionados à inclusão. Na pesquisa, foi constatado que alunos e professores reconhecem a superdotação por meio da capacidade cognitiva superior e pelo destaque acadêmico; eles revelaram como elementos favoráveis a essa inclusão professores preparados, boa prática pedagógica e a diversidade de materiais para pesquisa em sala de aula. Lima (2010) chama a atenção para o fato de que, apesar de estarem efetivamente matriculados, os alunos com AH/SD não têm recebido a atenção que necessitam para aplicar suas potencialidades. Os resultados mostram que a inclusão escolar de alunos com AH/SD, nas escolas públicas regulares, ainda encontra dificuldades para efetivar-se conforme a proposta da educação inclusiva.

As pesquisas de Perez (2008) e Chagas (2008) apresentam resultados que apontam a família e a escola como essenciais na promoção do desenvolvimento saudável e a inclusão social. Ainda na perspectiva da inclusão, Rech (2007) acompanhou o ingresso precoce de uma aluna no 1을 Ano do Ensino Fundamental e buscou fazer o levantamento das características de AH/SD e verificar os dispositivos disciplinares utilizados pela professora. A autora constatou que apesar de ter sido incluída, surgiram várias situações de exclusão em sala de aula.

Portanto, uma vez superada a ideia da segregação, vemos pelas pesquisas que atualmente se reconhece a importância da inclusão dos alunos com diferentes necessidades especiais nas salas de aula regulares para que, assim, sejam preparados para a vida em sociedade. No entanto, a inclusão ainda está muito limitada às discussões acadêmicas e trabalhos científicos, não acontecendo efetivamente no dia a dia escolar. De acordo com as pesquisas apresentadas, é possível destacar que inúmeras são as barreiras e as dificuldades que ainda impedem essa inclusão; dentre estas, está a formação inicial e continuada dos professores.

A identificação dos alunos com AH/SD corresponde à outra categoria explorada. A devida identificação desses alunos revela, de certa forma, a concepção adotada acerca deste público e, por consequência, o atendimento educacional especializado que lhe será dirigido.

Um dos primeiros estudos voltados para a identificação de alunos com AH/SD é o trabalho realizado por Delou (1987), citado em Anjos (2011), que utilizou uma abordagem qualitativa para a identificação dos alunos superdotados. Por outro lado, em Pérez (2008) é citada a tese de Viana (2005), que apresenta forte incidência de preconceitos na identificação das $A H / S D$, baseada no rendimento acadêmico dos alunos e a predileção por alunos do gênero masculino. Nesses trabalhos, fomos apresentadas a alguns mitos na área das AH/SD.

A identificação das AH/SD ainda em idade precoce foi objeto de estudo para Vieira (2005), que buscou identificar características de superdotação a partir de múltiplas expressões, considerando a Teoria das Inteligências Múltiplas, de Howard Gardner e a Teoria dos Três Anéis, de Joseph Renzulli. Martins (2013) parte 
da concepção de superdotação de Renzulli e, por meio de uma revisão bibliográfica, levanta as principais características indicativas de superdotação. Sua busca foi baseada em autores como: Novaes (1979); Delou (1987); Brasil (2002); Aranha (2005); Vieira (2005); Mosquera e Stobäus (2006); Panzeri (2006); Chagas (2007); Fleith (2007); Ourofino (2007); Nakano e Wechsler (2007); Virgolim (2007); Pérez (2008); Chagas e Fleith (2009); Pérez (2009); Almeida e Oliveira (2010); Freitas e Pérez (2010); García (2011); Sabatella (2012).

Nas pesquisas de Marques (2010) e Pérez (2004), o foco está voltado para a identificação de alunos com indicativos de AH/SD, analisando as variáveis e características consideradas no processo e buscando estratégias de melhorias para os instrumentos de identificação comumente utilizados nas escolas. Partindo da Teoria Triádica de Superdotação idealizada por Renzulli e da Teoria das Inteligências Múltiplas de Gardner, Fernandes (2014) elaborou um instrumento de avaliação educacional diagnóstica de altas habilidades para alunos com surdez. Destacou uma mudança significativa na forma de se relacionar com esses alunos que, tradicionalmente, são definidos pelos seus déficits e não por suas capacidades.

Araujo (2014) também parte da concepção de superdotação de Renzulli e buscou contribuir com o processo de identificação ao propor estratégias pedagógicas para a identificação em uma formação continuada para os professores. Questionando os modelos de identificação trazidos de outros países, Farias (2012) e Christofoletti (2012) apresentam a criação de instrumentos próprios para selecionar alunos com AH/SD. Dessa forma, a contribuição das pesquisas relativas ao processo de identificação de alunos com AH/SD ocorre no sentido em que revelam alguns mitos que perduraram/perduram acerca da percepção das $\mathrm{AH} / \mathrm{SD}$, bem como revelam as concepções adotadas atualmente sobre a temática das $\mathrm{AH} / \mathrm{SD}$, o que, por sua vez, irá interferir diretamente nos programas de atendimento.

A categoria do Atendimento Educacional Especializado (AEE) demonstra a preocupação com o atendimento adequado aos alunos com AH/SD, no sentido de reconhecer suas necessidades educacionais especiais, desvendando, assim, mitos como o de que este aluno tem facilidade em todas as áreas e aprende sozinho. A pesquisa de Magalhães (2006) avaliou os aspectos positivos e as limitações do Programa de Atendimento ao Superdotado da Secretaria de Estado da Educação do Distrito Federal, no período de 1991 a 2002. O aspecto de maior ênfase na pesquisa apontou como discriminatórias as questões que priorizam recursos financeiros para àqueles alunos com dificuldades de aprendizagem em detrimento de alunos superdotados, sendo que ambos possuem necessidades educacionais especiais. A pesquisa contribuiu, também, para constatar a necessidade e a importância de identificar e oferecer um programa especializado como forma de ajustamento e inclusão social do público das AH/SD.

Lyra (2012) teve por objetivo analisar como se realiza o atendimento aos alunos com $\mathrm{AH} / \mathrm{SD}$ na rede pública estadual de ensino, da região metropolitana de Londrina/PR. Os resultados da pesquisa evidenciaram a necessidade de investimento na qualificação dos professores que reconhecem dificuldades para a identificação e o encaminhamento ao atendimento dos alunos com AH/SD. Como pontos positivos, foram destacados o comprometimento e o empenho dos profissionais do Núcleo de Atividades de Altas Habilidades/Superdotação 
(NAAH/S) e os aspectos que precisam de atenção são os investimentos financeiros para melhorias nas estruturas físicas e materiais para o trabalho do NAAH/S.

Silva (2014a) analisou o papel do AEE para o desenvolvimento da suplementação pedagógica dos alunos com AH/SD, bem como as políticas e práticas utilizadas no processo de ensino e de aprendizagem desses sujeitos. Os resultados indicam, entre outros aspectos, que o AEE favorece a organização estrutural do serviço e a formação dos professores, mas também traz alguns desafios, como a restrição dos atendimentos e a falta de recursos adequados para atender o alunado com AH/SD. Klagenbeg (2014) também aponta para a fragilidade do sistema para identificar e atender os sujeitos com AH/SD na Rede Municipal de Canoas/RS.

Marques e Almeida (2014) apresentaram um levantamento com a localização de programas de atendimento às AH/SD, tendo como foco as regiões do Brasil. Esse estudo contribuiu de forma significativa ao apresentar um panorama em nível nacional, permitindo conhecer as regiões mais desenvolvidas em detrimento de outras nas quais ainda há muito por ser feito em relação a essa temática.

Por meio de um estudo de caso, Negrini (2015) realizou uma pesquisa qualitativa de análise documental e pesquisa de campo com alunos com AH/SD, seus professores e um coordenador de escola. Seu o objetivo foi analisar como é constituído o currículo escolar e se ele tem atendido às necessidades educacionais desses alunos. A autora percebeu a necessidade de qualificação das práticas pedagógicas e propôs, como uma alternativa, a espiral das perspectivas curriculares.

De modo geral, as pesquisas apontam e reconhecem a importância do AEE como forma de complementar o ensino oferecido na rede regular de ensino. Em contrapartida, os estudos apresentam também as limitações, como a insuficiência de oferta de atendimento e a falta de investimentos em materiais específicos para os superdotados. A qualificação dos professores do ensino regular também foi apontada como necessidade básica, tanto para a identificação dos alunos com $\mathrm{AH} / \mathrm{SD}$ quanto para trabalhar com estratégias pedagógicas adequadas para as necessidades educacionais desses alunos.

As pesquisas relativas à Psicologia e seus aspectos subjetivos como a de Santos (2015b), Aspesi (2003), Chagas (2003), Bahiense (2013), Borges (2012), Miranda (2013), Viana (2003), Monte (2009), Oliveira (2016), lorio (2015) e Franke (2013) estão normalmente direcionadas a tratar dos aspectos emocionais e comportamentais dos indivíduos com AH/SD nas relações destes com a família e a escola. Os resultados, de modo geral, chamam a atenção para o papel que a família e a escola podem desempenhar no estímulo de habilidades, talentos e interesses. Nessa categoria, vemos a importância da devida identificação e atendimento educacional especializado para os alunos com AH/SD.

As políticas públicas voltadas para a Educação Especial buscam, de certa forma, garantir a inclusão dos indivíduos com AH/SD para que tenham acesso a uma educação de qualidade que atenda suas necessidades educacionais especiais. Os resultados das pesquisas revelam importantes avanços nos últimos anos; entretanto, problemas, como a falta de recursos nas escolas e a falta de formação dos professores, fazem com que, na prática, muitas escolas ainda estejam longe de exercerem a inclusão de alunos com AH/SD, como vemos em Mani (2015), 
Negrini (2015), Bendinelli (2012), Santos (2016), Fagliari (2012), Schreiber (2012), Oliveira (2015) e Garcia (2015).

A formação docente tem sido apontada como um dos grandes gargalos para a garantia da inclusão dos alunos com AH/SD, uma vez que interfere diretamente na identificação destes alunos bem como na promoção do atendimento educacional adequado. Os resultados apontam a falta de clareza na concepção dos professores acerca das $\mathrm{AH} / \mathrm{SD}$ e estes reconhecem a necessidade de ações formativas relativas à educação inclusiva, como apontam Amaral (2013), Forno (2011), Souza (2010), Procópio (2010), Pessanha (2015), Campos (2016), Silva (2012) e Silva (2014b). Talvez um dos grandes desafios para os docentes é o acesso a formações que ampliem suas competências para compreender os caminhos do ensinar e do aprender para todos os seus alunos.

Já em número bastante reduzido, temos a categoria das Altas Habilidades/Superdotação associadas a outras necessidades educacionais. Poucos estudos que tratam de casos de dupla excepcionalidade foram encontrados. Cabe destacar as pesquisas de Martins (2016), Pinho (2016) e Silveira (2014), que abordam as AH/SD acompanhadas da Síndrome de Asperger. Enquanto Martins (2016) discorre sobre as dificuldades sociais enfrentadas por esses indivíduos e sugere intervenções pedagógicas, Pinho (2016) apresenta uma lista base de características observáveis em alunos com AH/SD associada à Síndrome de Asperger, como uma ferramenta para uso nas escolas. Silveira (2014) investiga o processo de aprendizagem de uma criança com Altas Habilidades/Superdotação e Transtorno de Asperger e, nos resultados, destaca a importância de qualificar o atendimento educacional especializado por meio da formação dos professores.

Negrini (2009) buscou organizar e implementar estratégias para a identificação de alunos com AH/SD em uma escola de surdos. A autora destaca que o processo de identificação destes alunos possibilita que se possa pensar em estratégias curriculares para atender a esta demanda, oportunizando possibilidades de aprendizagens diferenciadas. Rangni (2011) também teve como objetivo reconhecer os alunos com talento e perdas auditivas incluídos em escolas regulares e, uma vez tendo os alunos identificados, chama a atenção para o atendimento especializado e o desenvolvimento de seus talentos.

Costa (2013) analisa, em seu estudo crianças, índigo e com AH/SD e busca elaborar um elenco de características da criança índigo, analisar como os professores percebem as características índigo e de AH/SD, evidentes no contexto escolar, e compreender como as relações das características índigo e de AH/SD interferem no processo de escolarização destes sujeitos. Taucei (2015) investiga como são as interações nos contextos familiar, social e escolar de estudantes com AH/SD e dislexia. A autora destaca que a interação familiar, apesar das dificuldades, evidencia envolvimento profundo com a qualidade de vida dessas crianças. Em relação às interações na escola, essas se apresentam extremamente conturbadas, visto que não são compreendidas por muitos professores. Há um desconhecimento dos docentes em relação à realidade da dupla excepcionalidade. Quanto às interações no ambiente social, ela ressalta a dificuldade dessas crianças, expressa em tendência ao isolamento e introversão.

Ourofino (2005) comparou alunos superdotados, hiperativos e superdotados/hiperativos em relação à criatividade, inteligência, autoconceito, déficit de atenção e hiperatividade/impulsividade, comportamento antissocial e 
dificuldades de aprendizagem. Foi possível destacar particularidades para cada uma das categorias e, com isso, a autora chama a atenção para o devido atendimento educacional especializado.

De acordo com as pesquisas encontradas, podemos observar que a dupla excepcionalidade se torna um grande desafio para os professores, pois muitas vezes ela não é reconhecida. Mais uma vez, a formação docente e continuada é fundamental para que os professores estejam preparados para reconhecê-la e para que saibam trabalhar de forma a garantir a inclusão desses alunos, tendo contemplado suas necessidades.

Poucos são os registros da categoria que aborda estudos comparativos entre "superdotados" $e$ "não superdotados". Pereira (2016) realizou um trabalho de intervenção com o uso da robótica e comparou os alunos com AH/SD com os demais alunos. Os resultados apontaram distintos graus de interesse e de participação dos dois grupos, com considerável desempenho daquele com AH/SD. Oliveira (2015), em sua pesquisa, buscou identificar o nível de aptidão musical e as diferenças na superdotação para música nos alunos que frequentaram o Programa de Atenção a Alunos Precoces com Comportamento de Superdotação (PAPCS), da Faculdade de Filosofia e Ciências - UNESP, Campus de Marília, em 2013. Os resultados apontaram um aluno com AH/SD com os melhores resultados dentre todos os participantes pesquisados, inclusive quando comparado a outro grupo de alunos com experiência musical. Gonçalves (2010) realizou um estudo comparativo entre alunos superdotados e não superdotados em relação à criatividade e inteligência e apontou diferenças significativas. Chamou atenção para a implementação de estratégias educacionais de forma a contemplar as habilidades e os estilos de aprendizagem de cada um desses indivíduos. É importante salientar que os estudos comparativos entre alunos com AH/SD e os demais alunos são cada vez mais escassos. Atualmente, os principais objetivos das pesquisas estão voltados para conhecer e compreender as características da população com AH/SD e, assim, qualificar esta categoria sem compará-los aos demais alunos, mas buscando sua inclusão.

Os trabalhos de levantamento bibliográfico na área das AH/SD são importantes fontes de revisão de literatura, pois nos fornecem informações de como vem sendo exploradas as pesquisas nessa área e apontam tendências de investigações futuras. Tsuboi (2002), da Universidade Federal do Rio de Janeiro (UFRJ), fez uma investigação no campo da produção acadêmica dos programas de pós-graduação das universidades brasileiras sobre a temática das AH/SD com o objetivo de mapear os trabalhos elaborados sob as formas de tese e dissertação, dos anos 1980 a 2001. Seu objetivo era apresentar contribuições em relação ao atendimento educacional especializado aos portadores de AH/SD, bem como a busca por uma teoria mais completa, abrangendo a inteligência humana, uma melhor compreensão das AH/SD e uma análise da legislação educacional vigente. Por meio da metodologia de pesquisa bibliográfica, a autora organizou e apresentou os trabalhos em categorias de acordo com as pesquisas realizadas, o que contribui para uma visão das produções acadêmicas na área, bem como despertou novos olhares para áreas ainda pouco exploradas.

Anjos (2011) fez um levantamento para identificar, por meio das abordagens teórico-metodológicas, o perfil epistemológico e as tendências da investigação das dissertações e teses, defendidas nos programas de pós-graduação no Brasil, que estudaram o atendimento para pessoas com AH/SD no período de 1989 a 2009. A 
pesquisa de Anjos (2011) complementa o trabalho de Tsuboi (2002) com o levantamento de pesquisas até o ano de 2009. Zavitoski (2015), com o objetivo de analisar dissertações e teses brasileiras até então desenvolvidas, e Carneiro (2015), que buscou avaliar os programas de atendimento ao superdotado no Brasil, chegaram a resultados muito parecidos ao constatar que Renzulli é o aporte teórico mais utilizado na maioria das pesquisas e que, no Brasil, as regiões com o maior número de pesquisas na área são as regiões Sudeste e Centro-Oeste.

Dentro das AH/SD, um campo específico ainda pouco explorado são as Altas Habilidades/Superdotação em Matemática. Percebemos que são restritos os estudos exploratórios acerca de metodologias ou estratégias pedagógicas adotadas na disciplina de Matemática em programas de AEE para alunos com $\mathrm{AH} / \mathrm{SD}$. Entendemos que essa se configura como uma importante área de pesquisa a ser explorada com o objetivo de compreender melhor como este aluno pensa, articula e age diante das diferentes situações matemáticas que Ihe sejam propostas. Compreender a forma e as estratégias empregadas por esse aluno pode contribuir para o aperfeiçoamento dos programas de enriquecimento e para propiciar o desenvolvimento de suas potencialidades. Além disso, considerando a perspectiva inclusiva, as ações planejadas podem ser utilizadas para ampliar o conhecimento de todos os alunos.

No Brasil, podemos destacar algumas pesquisas, como a de Santos (2016) que investiga o conceito de superdotação relacionado à Lógica Clássica, na concepção de professores do Ensino Médio. Os resultados apontam concepções primitivas acerca das AH/SD, uma vez que estão vinculadas à capacidade cognitiva dos tipos lógico-matemática ou linguística.

Monteiro (2016) buscou conhecer as habilidades matemáticas dos alunos com $\mathrm{AH} / \mathrm{SD}$, refletir sobre as práticas pedagógicas adotadas nas aulas da sala de recursos para $\mathrm{AH} / \mathrm{SD}$ em Matemática e propôs também um programa de intervenção, intitulado "Probabilidade e a construção de jogos para um torneio". De acordo com os resultados, o projeto se mostrou apropriado, corroborando a necessidade de investimento no que se refere à capacitação dos professores para a adequação de estratégias pedagógicas para o desenvolvimento de alunos com $\mathrm{AH} / \mathrm{SD}$.

Stadler (2016) objetivou investigar o raciocínio lógico matemático em um grupo de 10 alunos com AH/SD, participantes de uma Sala de Recursos Multifuncional. Foram utilizados jogos e situações matemáticas para observar o desenvolvimento cognitivo do aluno quanto ao raciocínio lógico matemático. Os resultados demonstraram que há inteligências acadêmicas em diversas áreas do conhecimento, revelando características das inteligências múltiplas de Gardner e as características dos três anéis de Renzulli: habilidades acima da média, envolvimento com a tarefa e criatividade.

Rizo (2016) objetivou apontar como são identificados, assistidos e realizados os trabalhos junto aos alunos com indícios de AH/SD, problematizando os saberes matemáticos produzidos por eles em uma escola pública de referência do Espírito Santo. O autor ressalta que, a partir de atividades enriquecedoras, é possível estimular habilidades matemáticas, oportunizando, assim, o desenvolvimento de talentos e novas ideias.

Machado (2013) teve como objetivo compreender, por meio da epistemologia genética de Piaget, os aspectos cognitivos envolvidos em tarefas que continham 
resolução de problemas, buscando identificar as estratégias cognitivas e metacognitivas utilizadas na resolução de situações problema em matemática, com vistas à orientação aos profissionais envolvidos no contexto regular de ensino, dentro de uma prática educacional inclusiva. $O$ aporte teórico de sua pesquisa se apoia na teoria piagetiana e nos estudos de Sternberg e Davidson (1985), na Teoria Triárquica da Inteligência de Sternberg (1986), bem como na Teoria dos Três Anéis de Renzulli (1986).

Em Rosa (2014), é possível observar um estudo qualitativo a partir das narrativas de professores que ensinam matemática para compreender suas concepções acerca da inclusão escolar e o processo de ensino e aprendizagem de matemática de alunos com deficiência, transtorno global do desenvolvimento, $\mathrm{AH} / \mathrm{SD}$. Desse modo, vimos que as pesquisas brasileiras com enfoque nas AH/SD em Matemática apresentam algumas formas de identificação e propostas de intervenção pedagógica, porém ainda são escassas as contribuições na área, prevalecendo dúvidas relativas à identificação de alunos com AH/SD em Matemática, estratégias para identificação desses alunos, metodologias de ensino, dificuldades de aprendizagem, entre outras. Para atender a essas necessidades, se faz necessária a ampliação do campo de buscas.

\section{Bases internacionais consultadas}

A motivação da busca textual ter se expandido também para bases internacionais esteve atrelada ao fato de poucas pesquisas brasileiras estarem direcionadas aos estudos das AH/SD em Matemática. Como um dos objetivos específicos deste estudo era aprofundar os conhecimentos acerca das AH/SD em Matemática, sentimos a necessidade de ampliar os horizontes.

No contexto internacional, o filtro de buscas priorizou as pesquisas sobre as AH/SD em Matemática. Consultamos a Networked Digital Library of Theses and Dissertation (NDLTD), a qual reúne teses e dissertações do mundo todo. Com a palavra-chave giftedness [superdotação], foram encontrados 282 registros, sendo que o Australiasian Digital Theses Program e o Instituto Brasileiro de Informação em Ciência e Tecnologia (IBICT) representam 31,5\% das publicações, merecendo destaque esses dois países (Austrália e Brasil) pelo quantitativo de publicações na área das $\mathrm{AH} / \mathrm{SD}$.

Dos registros encontrados na NDLTD, nos detemos nas publicações relativas somente às AH/SD em Matemática, apresentando, assim, um breve relato de como estão sendo exploradas as pesquisas acerca das AH/SD em Matemática no contexto mundial.

Freiman (2003), em seu estudo realizado em Montreal no Canadá, buscou interpretar o trabalho matemático das crianças com AH/SD e as situações didáticas favoráveis para promover habilidades matemáticas, a fim de desenvolver estratégias de ensino eficientes para os alunos superdotados. Em seus resultados, constatou nesses alunos das séries iniciais: precocidade matemática, pensamento em conceitos e relações, alta motivação e perseverança, mentes sistemáticas e reflexivas.

O estudo realizado por Daniel (2006), da Universidade de Otago na Nova Zelândia, revela um estudo de caso com 10 estudantes identificados com AH/SD em Matemática e que participam da Olimpíada Internacional de Matemática. Nas análises das narrativas, o autor destacou que poucos pais apresentavam alguma 
habilidade em Matemática e não sabiam explicar o fascínio dos filhos pelos números. Quanto à escola, havia relatos de experiências desagradáveis e a maioria dos alunos teve poucas atividades de incentivo e estímulo, sendo que sua habilidade matemática nem sempre era reconhecida pelos professores. A maioria demonstrou interesse por atividades culturais e físicas que permitiam o desenvolvimento individual e a perseverança do indivíduo. Em grande parte, eles foram motivados a encontrar novas formas de integrar conhecimentos diversos.

Kotsiras (2007), em sua dissertação pela Universidade de Melbourne da Austrália, analisou, de forma quantitativa, os benefícios dos programas de aceleração no desempenho em Matemática. Os resultados sugerem que a aceleração apresenta efeitos positivos quando compara resultados de testes aos quais foram submetidos os sujeitos acelerados e os que não estavam acelerados, sendo estes de mesma faixa etária.

Na Nova Zelândia, encontramos a tese de Bicknell (2009), pela Universidade de Massey, que realizou um estudo de caso predominantemente qualitativo, no qual, por meio de documentos e entrevistas, buscou analisar múltiplas perspectivas sobre a educação de estudantes identificados com AH/SD em Matemática: as características desses estudantes; a identificação; as metodologias educacionais utilizadas; o envolvimento dos pais e a mudança de escola. Os resultados da pesquisa mostram que não há uma compreensão abrangente por parte das escolas e professores sobre as características dos estudantes matematicamente talentosos. Nos processos de identificação, na maioria das escolas, não há uma abordagem múltipla. Os programas de atendimento são muito variáveis e dependem da identificação, organização escolar, do conhecimento dos professores, dos recursos, entre outros. Os pais desempenham papel fundamental no sentido de serem os motivadores e provedores de recursos e estímulos que favoreçam o desenvolvimento.

Dimitriadis (2010), da Universidade de Brunel na Inglaterra, desenvolveu um estudo das estratégias utilizadas para a oferta educativa para crianças superdotadas em matemática em um grupo de escolas do ensino fundamental da Inglaterra. Foi realizada uma revisão de literatura relacionada à teoria internacional e a pesquisas existentes na educação de alunos com AH/SD, bem como um trabalho empírico para o ensino de matemática. Sua pesquisa verificou que, embora sem formação específica, os professores e os coordenadores escolares receberam treinamento para trabalhar com crianças matematicamente talentosas, como prevê o programa nacional de formação. Nas salas de aula, verificou-se que o nível de confiança e experiência dos professores, o nível de atenção dado às crianças superdotadas e o tamanho das turmas foram fatores que contribuíram para o progresso, percepções e atitudes de crianças que foram identificadas com AH/SD.

Há escassez de pesquisas que investigam aspectos do atendimento para crianças dotadas e talentosas, especialmente em matemática, no Reino Unido. Ao abordar especificamente este tema, o estudo de Dimitriadis (2010) traz uma contribuição distinta para a literatura atual em ambos os aspectos de compreensão da superdotação matemática e apresenta exemplos para organizar e ensinar matemática para crianças superdotadas em níveis cognitivos mais elevados, dentro de salas de aula regulares, podendo, inclusive, ser de interesse para o público internacional, incluindo os países onde não existem políticas de atendimento para alunos matematicamente talentosos. 
Hui-Kuo Su (2011) realizou um estudo em Taiwan com o objetivo de identicar como os pais descobrem as AH/SD matemática em seus filhos. Nos questionários aplicados, o autor obteve as seguintes conclusões: os pais percebem que seus filhos entendem os conceitos matemáticos rapidamente, têm habilidades de cálculo, tem bom raciocínio lógico, demonstram pensamentos flexíveis e exibem uma afinidade com os números. Eles percebem que seus filhos fazem perguntas sobre matemática e jogos matemáticos/atividades, são entusiastas na resolução de problemas matemáticos, tentam resolver problemas difíceis, são comprometidos com o autodesafio e dedicados a estudar conhecimentos matemáticos. Os pais destes alunos também revelaram que incentivam seus filhos a ler livros relacionados à matemática, fornecem jogos e brinquedos destinados à educação matemática, ensinam-lhes matemática e criam ambiente de aprendizagem da matemática na vida cotidiana. Responderam ainda que concordariam com a admissão precoce dos filhos na escola, com programas de aceleração e também com cursos matemáticos avançados, oferecidos a seus filhos por instituições acadêmicas. A maioria dos pais também encaminharia o filho a uma escola especializada no ensino da matemática, compraria livros de testes de matemática, incentivaria a participar de concursos e competições e contrataria tutores para o acompanhamento do desenvolvimento do potencial dos filhos. De acordo com os pais, são duas as razões principais para o grande interesse de seus filhos pela aprendizagem da matemática: talento matemático excepcional $(61,46 \%)$ e excelente ambiente de aprendizagem (70,83\%).

O estudo realizado por Erasmos (2013), em Pretória na África, procurou determinar o impacto de programas de enriquecimento para alunos com AH/SD em Ciências. Com um grupo experimental, que foi submetido a um programa de enriquecimento e foi comparado com outro grupo de alunos, também com AH/SD em ciências, mas que não recebeu o enriquecimento, esse estudo observou, por meio de um pós-teste, que todos aqueles alunos que participaram do programa de enriquecimento tiveram melhor desempenho. Isso ressalta a importância de ações pedagógicas para aprofundar e ampliar a compreensão dos conceitos.

Rundblad (2015), na Suécia, investiga como quatro diretores de escola trabalham para promover alunos com AH/SD em Matemática. O estudo investigou se essas quatro escolas têm estratégias em comum para identificar esses estudantes e ações educativas para estimular e promover o desenvolvimento de seu potencial. Os resultados apontam que os diretores estão inseguros e não sabem descrever como identificam os alunos matematicamente talentosos e também não possuem um método diferenciado de ensino para lidar com esses alunos. As estratégias utilizadas nas escolas envolvem a participação do professor da rede regular de ensino e do professor da educação especial que aplicam testes, formam grupos de matemática de alto nível e, assim, buscam identificar e estimular matematicamente os alunos talentosos.

Além das teses e dissertações pesquisadas nas bases consultadas, cabe destacar também especialistas que atuam no Brasil e contribuem com suas pesquisas na elaboração de livros, visando à formação de professores e profissionais da educação para a identificação dos alunos com AH/SD e o devido atendimento educacional especializado, com vistas ao pleno desenvolvimento das potencialidades desses alunos, entre os quais, Alencar $(2001,2005,2007)$ Alencar e Fleith (2001, 2005), Fleith (2001; 2007), Fleith e Alencar (2007), Delou (1996, 
2001, 2007), Pérez $(2004,2008,2014)$ Pérez e Freitas $(2009,2011)$, Virgolim (2005, 2007, 2010).

\section{CONSIDERAÇÕES FINAIS}

De acordo com o levantamento bibliográfico realizado, foi possível constatarmos que a representação social ao buscar compreender a percepção e a autopercepção do público das AH/SD é a categoria de pesquisas mais explorada no Brasil. Percebe-se, assim, a preocupação para compreender esses indivíduos, suas qualidades, como aprendem e como se relacionam. Ao reconhecê-los como um grupo social com características similares, os pesquisadores apontam que se faz necessário também conhecer e reconhecer suas necessidades educacionais especiais.

As categorias como inclusão e identificação de alunos com AH/SD também têm sido tema de pesquisas brasileiras. Há estudos investigando os processos de identificação e sugerindo métodos para o reconhecimento de alunos com AH/SD, desenvolvidos com a preocupação de que esses alunos sejam devidamente incluídos no processo educacional. Estas pesquisas também têm contribuído para que muitos mitos acerca dos indivíduos com AH/SD sejam desmistificados, favorecendo o reconhecimento das necessidades especiais desse grupo.

De acordo com as pesquisas levantadas, o Atendimento Educacional Especializado tem apontado alguns gargalos no Brasil. Algumas regiões - como Sudeste e Centro-Oeste - têm apresentado grande número de projetos, tanto em instituições públicas quanto privadas com AEE para alunos com AH/SD. Entretanto, nas regiões Norte e Nordeste, os programas de AEE ainda estão sendo introduzidos a passos lentos. Outro contratempo apontado na tentativa do AEE é a falta de formação dos professores para atuarem com esses alunos. Pesquisas nesta categoria também apontam este problema. De modo geral, as pesquisas nessa área apontam que os professores não têm sido preparados para trabalhar com alunos que apresentem AH/SD. As dificuldades se iniciam desde o processo de identificação até o atendimento especializado que, muitas vezes, não atende às necessidades desse público.

As pesquisas apontam, ainda, que a efetivação de políticas públicas voltadas ao atendimento do aluno com AH/SD tardaram para serem implantadas no país e, com isso, temos hoje ainda muitos professores que não se sentem preparados para identificar de forma correta o aluno com AH/SD, bem como para oferecer-lhe atendimento especializado de acordo com suas necessidades educacionais especiais.

Áreas pouco exploradas nas pesquisas brasileiras, também, merecem destaque, como é o caso das Altas Habilidades/Superdotação em Matemática. No contexto mundial, destacamos países com pesquisas voltadas às metodologias e estratégias de ensino, adotadas pelos educadores nas aulas de matemática para contemplar as necessidades desse público. No Brasil, ainda há um vasto campo a ser explorado na perspectiva dos programas de atendimento para complementar o ensino regular de matemática, de forma que atenda às necessidades especiais desses alunos.

No entanto, para o trabalho com as $\mathrm{AH} / \mathrm{SD}$ na perspectiva da educação inclusiva, ainda há um longo caminho a ser percorrido. As pesquisas, nas mais 
diversas áreas, têm contribuído para os avanços percebidos nas últimas décadas, mas ainda há muito a se fazer, desde a devida identificação até o atendimento no AEE. Deste modo, todos os estudantes com AH/SD, das mais diversas regiões brasileiras, poderão ter suas necessidades educacionais atendidas. 


\title{
BIBLIOGRAPHIC REVIEW ON HIGH SKILLS/GIFTEDNESS WITH EMPHASIS ON MATHEMATICS
}

\begin{abstract}
Research in the High Skills/Giftedness (HS/G) field focused on contributing to special education, based on the inclusive education perspective, has stood out in recent decades. The aim of the current research is to present a bibliographic review by grouping the analyzed articles belonging to similar scientific fields in order to outline the main focus of studies about HS/G in Mathematics. It was done based on searches carried out in the Brazilian Digital Library of Theses and Dissertations (BDTD - Biblioteca Digital Brasileira de Teses e Dissertações), Capes Thesis Bank and repositories of different Brazilian universities such as UnB, UFSCar, UNESP, PUCRS, PUCSP, UNIFESP, UFSC, UFPR, UFSM, UFRGS and UFES. Searches were conducted from 2014 to 2017, based on descriptors such as High Skills and Giftedness. Content analysis stages comprised fluctuating readings and cores of meaning. Results have shown that social representation, identification and inclusion were the most explored categories in Brazil. Searches were extrapolated to the global context, but results have evidenced that studies in the High Skills/Giftedness field aiming at Mathematics remain scarce. This outcome has highlighted the need of conducting further studies addressing the development of teaching methodologies and enrichment programs to meet the needs of special educational students and to ensure the effective inclusion of individuals with HS/G in Mathematics.
\end{abstract}

KEYWORDS: High skills/giftedness. High skills/giftedness in Mathematics. Inclusive education. 


\section{REFERÊNCIAS}

AGUIAR, Wanda Maria Junqueira, OZELLA, Sergio. Núcleos de significação como instrumento para a apreensão da constituição dos sentidos. Periódicos eletrônicos de psicologia. Psicol. cienc. prof. v.26 n.2 Brasília jun. 2006. Disponível em: http://pepsic.bvsalud.org/scielo.php?script=sci arttext\&pid=S141498932006000200006. Acessado em: 25 mar. 2020.

ALENCAR, Eunice Maria Lima Soriano de. Indivíduos com Altas Habilidades/Superdotação: clarificando conceitos, desfazendo ideias errôneas. In: FLEITH, D. de S. (org). A construção de práticas educacionais para alunos com altas habilidades/superdotação: v. 1: Orientação a professores. Brasília: Ministério da Educação, Secretaria de Educação Especial (MEC/SSESP), 2007, p.13-23.

ALENCAR, Eunice Maria Lima Soriano de. Criatividade e educação de superdotados. Petrópolis, RJ: Ed. Vozes, 2001.

ALENCAR, Eunice Maria Lima Soriano de. Criatividade e sua importância na educação do superdotado. ANEIS - Associação Nacional para o Estudo e a Intervenção na Sobredotação, Braga, v. 6, p. 27-40, 2005.

ALENCAR, Eunice Maria Lima Soriano de. A atenção ao aluno que se destaca por um potencial superior. Cadernos de Educação Especial, Santa Maria, n. 27, 2005. Disponível em: http://www.redalyc.org/pdf/3131/313127397010.pdf Acesso em: 04 nov. 2016.

ALENCAR, Eunice Maria Lima Soriano de; FLEITH, Denise de Souza. Superdotados: determinantes, educação e ajustamento. 2. ed. São Paulo: EPU, 2001.

ALENCAR, Eunice Maria Lima Soriano de; FLEITH, Denise de Souza. Práticas pedagógicas que promovem a criatividade segundo professores de ensino fundamental. Relatório de Pesquisa. Conselho Nacional de Desenvolvimento Científico e Tecnológico - CNPq. Brasília, 2005.

AMARAL, Alessandra da Silva Souza Avila. A formação do professor a partir do lúdico: um possível caminho para identificação de alunos com altas habilidades/superdotação. 2013, 128 f. Dissertação (Mestrado em Educação) Universidade Federal do Rio de Janeiro, Rio de Janeiro, 2013. dissertações e teses no Brasil. 2011. 190 f. Tese (Doutorado em Educação Especial) - Centro de Educação e Ciências Humanas, Universidade Federal de São Carlos, São Paulo, 2011. 
ANTONIOLI, Camyla. Percepções dos profissionais de uma instituição de acolhimento sobre a criança com comportamento de Altas Habilidades/Superdotação. 2015, 91 f. Dissertação (Mestrado em Educação) Universidade Federal de Santa Maria, Santa Maria, 2015.

ARAÚJO, Marisa Ribeiro de. Avaliação e intervenção pedagógica para alunos com indicadores de altas habilidades/superdotação na perspectiva da educação inclusiva. 269 f. Tese (Doutorado em Educação Brasileira)- Universidade Federal do Ceará, Fortaleza, 2014.

ASPESI, Cristina de Campos. Processos Familiares Relacionados ao Desenvolvimento de Comportamentos de superdotação em Crianças de Idade Pré-Escolar. 2003, 86 f. Dissertação (Mestrado em Psicologia) - Universidade de Brasília, Brasília, 2003.

BAHIENSE, Taisa Rodrigues Smarssaro. Concepções sobre Altas Habilidades/Superdotação e Prática Docente. 2013, 178 f. Dissertação (Mestrado em Psicologia) -Universidade Federal do Espírito Santo, Vitória, 2013.

BAPTISTA, Mariana de Barros. Auto percepção e intervenção: um olhar sobre os jovens adolescentes com Altas Habilidades ou Superdotação. 2016, $73 \mathrm{f}$. Dissertação (Mestrado Profissional em Diversidade e Inclusão) - Universidade Federal Fluminense, Niterói, 2016.

BARRETO, Célia Maria Paz Ferreira. Altas Habilidades/Superdotação: Representações sociais dos professores do Colégio Pedro II. 2008, $181 \mathrm{f}$. Dissertação (Mestrado em Psicologia) - Universidade Salgado de Oliveira, Niterói, 2008.

BENDINELLI, Rosanna Cláudia. Redes de apoio e a política de inclusão escolar no município de São Paulo. 2012, 224 f. Dissertação (Mestrado em Educação) Universidade de São Paulo, São Paulo, 2012.

BICKNELL, Brenda Anne. Multiple perspectives on the education of mathematically gifted and talented students. 2009. BORGES, Wanessa Ferreira. Tecnologia assistida e práticas de letramento no atendimento educacional especializado. 2015, 201 f. Dissertação (Mestrado em Educação) - Universidade Federal de Goiás, Catalão, 2015.

BRASIL. Diretrizes gerais para o atendimento educacional aos alunos portadores de altas habilidades: superdotação e talentos. MEC/SEESP. Brasília/DF, 1995. 
CAMPOS, Eri Cristina dos Anjos. Formação continuada e permanente de professores do atendimento educacional especializado para práticas pedagógicas inclusivas. 2016, 128 f. Dissertação (Mestrado em Educação) Universidade do Planalto Catarinense, Lages, 2016.

CARNEIRO, Liliane Bernardes. Características e avaliação de programas brasileiros de atendimento educacional ao superdotado. 2015, $193 \mathrm{f}$. Tese (Doutorado em Processos de Desenvolvimento Humano e Saúde) - Universidade Federal de Brasília, Brasília, 2015.

CHAGAS, Jane Farias. Adolescentes talentosos: características individuais e familiares. $242 \mathrm{f}$. Tese (Doutorado em Processos de Desenvolvimento Humano e Saúde) - Universidade Federal de Brasília, Brasília, 2008.

CHRISTOFOLETTI, Rui Alexandre. Proposta e aplicação do método das hélices na identificação de estudantes talentosos. 2012, 120 f. Dissertação (Mestrado em Educação) - Universidade Federal de São Carlos, São Carlos, 2012.

CIANCA, Fabiane Silva Chueire. A percepção dos coordenadores de licenciaturas da UEL sobre Altas Habilidades/Superdotação. 2012, 122 f. Dissertação (Mestrado em Educação) -Universidade Estadual de Londrina, Londrina, 2012.

COELHO, Ana Alves da Silva. O modelo de enriquecimento escolar de Joseph Renzulli $\mathrm{e} o$ atendimento educacional especializado ao estudante com altas habilidades/superdotação: percepções docentes. 2015, 142 f. Dissertação (Mestrado em Educação) - Universidade Católica de Brasília, Brasília, 2015.

CORREIA, Gilka Borges. 0 autoconceito de estudantes com altas habilidades/superdotação na vivência da adolescência. 2011, 226 f. Tese (Doutorado em Educação) - Universidade Federal do Paraná, Curitiba, 2011.

COSTA, Anelise dos Santos. Crianças índigo e com Altas Habilidades/Superdotação: aproximações e distanciamentos no contexto educativo. 2013, 86 f. Dissertação (Mestrado em Educação) - Universidade Federal de Santa Maria, Santa Maria, 2013.

DANIEL, Carlos. The identification of mathematical ability and of factors significant in its nurture. Department of Mathematics \& Statistics - University of Otago, Nova Zelândia, 2006. 
habilidades/superdotação: volume 1: orientação a professores. Brasília: MEC, Secretaria de Educação Especial, 2007, p. 25-40.

DELOU, Cristina Maria Carvalho. Política Nacional de Educação Especial aplicada ao aluno de altas habilidades. Caderno de Educação Especial. Santa Maria, Rio Grande do Sul, 1996.

DELOU, Cristina Maria Carvalho. Sucesso e fracasso escolar de alunos considerados superdotados: um estudo sobre a trajetória escolar de alunos que receberam atendimento em salas de recursos de escolas da rede pública de ensino. 2001, 238 f. Tese (Doutorado em Educação: História, Política e Sociedade) - Pontifícia Universidade Católica de São Paulo, São Paulo, 2001.

DIMITRIADIS, Christos. Developing mathematical giftedness within primary schools: a study of strategies for educating children who are gifted in mathematics. 2010. Student thesis - Brunel University, Inglaterra, 2010.

ERASMOS, Charamba. The impact of enrichment programs on the performance of gifted science learners. 2013. 209 f. University of South Africa, 2013. FAGLIARI, Solange Santana dos Santos. A educação especial na perspectiva da educação inclusiva: ajustes e tensões entre a política federal e a municipal. 2012, $266 \mathrm{f}$. Dissertação (Mestrado em Educação) - Universidade de São Paulo, São Paulo, 2012.

FARIAS, Elidia Santos de. Elaboração de instrumento para identificação de alunos intelectualmente dotados por professores: estudo exploratório. 2012, 155f. Tese (Doutorado em Psicologia) - Centro de Ciências da Vida, Pontifícia Universidade Católica de Campinas, Campinas, 2012.

FERNANDES, Tereza Liduina Grigório. Capacidades silentes: avaliação educacional diagnóstica de altas habilidades em alunos com surdez. 2014. $330 \mathrm{f}$. Tese (Doutorado em Educação Brasileira) - Universidade Federal do Ceará, 2014.

FRANKE, Mônica Cecília Gonçalves Condessa. Altas Habilidades/Superdotação, intervenção psicopedagógica e aceleração de estudos: um estudo de caso. Curitiba. 2013, 122 f. Dissertação (Mestrado em Educação) - Universidade Federal do Paraná, Curitiba, 2013.

FREIMAN, Viktor. Identification and fostering of mathematically gifted children at the elementary school. 2003. $165 \mathrm{f}$. Dissertation - Department of Mathematics and Statistics. Concordia University, Montreal, 2003. 
FORNO, Letícia Fleig Dal. Precocidade na Educação Infantil: e agora professoras? 2011, 119 f. Dissertação (Mestrado em Educação) - Universidade Federal de Santa Maria, Santa Maria, 2011.

GARCIA, Dorcely Isabel Bellanda. Política nacional de educação especial na perspectiva da educação inclusiva na região sul do Brasil. 2015, 275 f. Tese (Doutorado em Educação) - Universidade Estadual de Maringá, Maringá, 2015.

GONÇALVES, Fernanda do Carmo. Estudo comparativo entre alunos superdotados e não superdotados em relação à criatividade, inteligência e percepção de clima de sala de aula para criatividade. 2010, 94 f. Dissertação (Mestrado em Processos de Desenvolvimento Humano e Saúde) - Universidade de Brasília, Brasília, 2010.

HUI-KUO, Su. The Study on Parents' Recognition and Facilitation to Their Children's Mathematical Giftedness. China, 2011.IORIO, Naila. de Mattos. Os sentidos subjetivos da avaliação psicológica em Altas Habilidades/Superdotação. 2015, undefined f. Dissertação (Mestrado em Psicologia) - Universidade Federal do Mato Grosso do Sul, Campo, 2015.

KLAGENBEG, Rosalina Moro. Altas Habilidades/Superdotação: o que se faz nas salas de recursos multifuncionais na rede municipal de ensino de Canoas/RS? 2014, 113 f. Dissertação (Mestrado em Educação) - Centro Universitário La Salle, Canoas, 2014.

KOTSIRAS, Angela. The effects of acceleration on students' achievement in senior secondary mathematics: a multilevel modelling approach. 2007, 189f. Masters Research thesis, Faculty of Education, The University of Melbourne, Austrália, 2007.

LIMA, Marcia Raika e Silva. Inclusão escolar de alunos com altas habilidades/superdotação em escolas públicas de Teresina-PI. 2010, 122 f. Dissertação (Mestrado em Educação) - Fundação Universidade Federal do Piauí, Teresina, 2010.

LYRA, Juliana Chueire Atendimento educacional especializado de alunos com altas habilidades/superdotação na cidade de Londrina, Paraná: um estudo de caso. 2013, 143 f. Dissertação (Mestrado em Educação) - Universidade Estadual de Londrina, Londrina, 2013.

MACHADO, Jarcí Maria. Habilidades cognitivas e metacognitivas do aluno com altas habilidades/superdotação na resolução de problemas em Matemática. 
MAGALHÃES, Marília Gonzaga M. S. de. Programa de atendimento ao superdotado da Secretaria de Estado de Educação do Distrito Federal (1991 2002): Inclusão social ou tergiversação burocrática? 2006. 394 f. Tese (Doutorado em Sociologia) - Departamento de Sociologia, Universidade Federal de Brasília, Brasília, 2006.

MANI, Eliane Morais de Jesus. Altas Habilidades ou Superdotação: Políticas públicas e atendimento educacional em uma diretoria de ensino Paulista. 2015, 176 f. Dissertação (Mestrado em Educação Especial) - Universidade Federal de São Carlos, São Carlos, 2015.

MANSO, Renata Sayão Araújo. Concepção e mitos sobre superdotação: o que pensam professores de crianças pequenas? 2012, $123 \mathrm{f}$. Dissertação (Mestrado em Educação) - Universidade Católica de Brasília, Brasília, 2012.

MARQUES, Clayton dos Reis. Levantamento de crianças com indicadores de altas habilidades em Jaboticabal/São Paulo. 2010. 176 f. Dissertação (Mestrado em Educação Especial) - Departamento de Educação e Ciências Humanas, Universidade Federal de São Carlos, São Paulo, 2010.

MARQUES, Clayton dos Reis; ALMEIDA, Maria Amélia. Localização de programas de atendimento em Altas Habilidades/Superdotação com foco nas regiões do Brasil. Disponível em: https://anpedsudeste2014.files.wordpress.com/2015/07/ clayton-dos-reis-marques-maria-amc3a9lia-almeida.pdf. Acesso: 18 jun. 2017.

MARTINS, Bárbara Amaral. Alunos precoces com indicadores de altas habilidades/superdotação no Ensino Fundamental I: identificação e situações (des) favorecedoras em sala de aula. 2013. 238 f. Dissertação (Mestrado em Educação) - Universidade Estadual Paulista, Marília, 2013.

MARTINS, Cláudia Solange Rossi. A Identificação do Aluno com Potencial para Altas Habilidades/Superdotação do Sistema Educacional Adventista em Manaus. 2006, 199 f. Dissertação (Mestrado em Educação) - Universidade Federal do Amazonas, Manaus, 2006.

MARTINS, Felipe Rodrigues. Clube de Ciências como ferramenta de iniciação científica para alunos superdotados e/ou com vocação científica. 2016, $118 \mathrm{f}$. Dissertação (Mestrado Profissional em Diversidade e Inclusão) - Universidade Federal Fluminense, Niterói, 2016. atividade para a sala de recursos multifuncional para altas habilidades/superdotação. 2016. 125 f. Dissertação (Mestrado em Ensino e 
Aprendizagem de Ciências Naturais e Matemáticas) - Universidade Estadual do Centro-Oeste, Paraná, 2016

MIRANDA, Cássio Eduardo Soares. Superdotação, Psicanálise e Nomeação. 2013, 320 f. Tese (Doutorado em Psicologia) - Universidade Federal do Rio de Janeiro, Rio de Janeiro, 2013.

MONTE, Patrícia Melo do. A aprendizagem do adolescente com altas habilidades: um estudo de caso na perspectiva da teoria da subjetividade. 2009, 167 f. Dissertação (Mestrado em Educação) - Universidade Federal do Piauí, Teresina, 2009.

NEGRINI, Tatiane. A escola de surdos e os alunos com altas habilidades/superdotação: uma problematização decorrente do processo de identificação das pessoas surdas. 2009, 151 f. Dissertação (Mestrado em Educação) - Universidade Federal de Santa Maria, Santa Maria, 2009.

NEGRINI, Tatiane. Problematizações e perspectivas curriculares na educação de alunos com altas habilidades/superdotação. 2015, $328 \mathrm{f}$. Tese (Doutorado em Educação) - Universidade Federal de Santa Maria, Santa Maria, 2015.

OLIVEIRA, Ana Paula de. Habilidades sociais e problemas de comportamento de estudantes com Altas Habilidades/Superdotação: caracterização, aplicação e avaliação de um programa de intervenção. 2016, 135 f. Dissertação (Mestrado em Psicologia do Desenvolvimento e Aprendizagem) - Universidade Estadual Paulista Júlio de Mesquita Filho, Bauru, 2016.

OLIVEIRA, Ângela do Nascimento Paranha de. Políticas de inclusão escolar na educação infantil: um estudo no município de Cariacica - ES. 2015, 196 f. Dissertação (Mestrado em Educação) - Universidade Federal do Espírito Santo, Vitória, 2015.

OUROFINO, Vanessa Terezinha Alves Tentes, GUIMARÃES, Tânia Gonzaga. Características intelectuais, emocionais e sociais do aluno com altas habilidades/superdotação. Em FLEITH, D. S. (Org.), A construção de práticas educacionais para alunos com altas habilidades/superdotação. Orientação a professores (pp 41 - 52). Brasília: MEC/SEESP, 2007.

OUROFINO, Vanessa Terezinha Alves Tentes, FLEITH, Denise de Souza. Um estudo comparativo sobre a dupla personalidade superdotação/hiperatividade. Revista Avaliação Psicológica, V. 4, N. 2, Porto Alegre, NOV. 2005. Disponível em: http://pepsic.bvsalud.org/scielo.php?script=sci arttext\&pid=S1677- 
PEREIRA, Vera Lúcia Palmeira. A Inclusão Educacional do Aluno Superdotado nos Contextos Regulares de Ensino. 2008, 118 f. Dissertação (Mestrado em Educação) - Universidade Católica de Brasília, Brasília, 2008.

PEREIRA, Wilson Roberto Francisco. Altas Habilidades/Superdotação e robótica: relato de uma experiência de aprendizagem a partir de Vygotsky. 2016, 2018 f. Dissertação (Mestrado Profissional em Educação e Novas Tecnologias) - Centro Universitário Internacional, Curitiba, 2016.

PÉREZ Susana Graciela Pérez Barrera. Gasparzinho vai à escola: um estudo das características do aluno com altas habilidades produtivo-criativo. 2004, $307 \mathrm{f}$. Dissertação (Mestrado em Educação) - Pontifícia Universidade Católica do Rio Grande do Sul, Porto Alegre, 2004.

PÉREZ Susana Graciela Pérez Barrera. Modelo de enriquecimento para toda a escola: Um plano abrangente para o desenvolvimento de talentos e superdotação. Revista Educação Especial, v. 27, n. 50, p. 539- 562 set. /dez. 2014.

PÉREZ Susana Graciela Pérez Barrera. Ser ou não ser, eis a questão: o processo de construção da identidade na pessoa com altas habilidades/superdotação adulta. 2008, 230 f. Tese (Doutorado em Educação) - Pontifícia Universidade Católica do Rio Grande do Sul, Porto Alegre, 2008.

PÉREZ Susana Graciela Pérez Barrera; FREITAS, Soraia Napoleão. Encaminhamentos pedagógicos com alunos com Altas Habilidades/Superdotação na Educação Básica: o cenário brasileiro. Educar em Revista, Curitiba: UFPR, n. 41, p. 109-124, jul./set. 2011.

PÉREZ Susana Graciela Pérez Barrera; FREITAS, Soraia Napoleão. Estado do conhecimento na área de altas habilidades/superdotação no Brasil: uma análise das últimas décadas. In: $32^{a}$ REUNIÃO ANUAL DA ANPED, 2009, Caxambu. Anais. 2009. Disponível em: <http://32reuniao.anped.org.br/arquivos/trabalhos/GT155514--Int.pdf>. Acesso em: 31 ago. 2016.

PESSANHA, Juliana Antunes. Altas habilidades na escola: Curso de Capacitação de Professores. 2015, 108 f. Dissertação (Mestrado Profissional em Diversidade e Inclusão) - Universidade Federal Fluminense, Niterói, 2015.

PINHO, Adriano de Castro. Dupla excepcionalidade: lista base de características observáveis em estudantes com Altas Habilidades ou Superdotação e Síndrome de Asperger - Ferramenta para uso na escola. 2016105 f. Dissertação (Mestrado Profissional em Diversidade e Inclusão) - Universidade Federal Fluminense, Niterói, 2016. 
PROCÓPIO, Marcos Vinícios Rabêlo. Altas Habilidades/Superdotação:

necessidades formativas dos professores de Ciências na perspectiva da Educação Inclusiva. 2010, 112 f. Dissertação (Mestrado em Educação em Ciências e Matemática) - Universidade Federal de Goiás, Goiânia, 2010.

RANGNI, Rosemeire de Araújo; COSTA, Maria Piedade Resende da. As altas habilidades/superdotação: entre termos e linguagens. Revista Educação Especial, v. 24, n. 41 , set. /dez. 2011.

$\mathrm{RECH}$, Andréia Jaqueline Devalle. Estudo de caso de uma criança com características de altas habilidades: problematizando questões referentes à inclusão escolar. 2007, 153f. Dissertação (Mestrado em Educação). Universidade Federal de Santa Maria, Santa Maria, 2007.

RENZULLI, J. S. What makes giftedness? Reexamining a definition. Phi Delta Kappan, 60 (3), 180-184, 1978.

RIZO, Welington Fraga. Saberes matemáticos produzidos por alunos com indícios de altas habilidades/superdotação: uma experiência com alunos do Ensino Médio na disciplina de Cálculo I. 2016. 96 f. Dissertação (Mestrado Profissional em Gestão Social, Educação e Desenvolvimento Regional) Faculdade Vale do Cricaré, São Mateus, 2016.

ROSA, Erica Aparecida Capasio. Professores que ensinam matemática e a inclusão escolar: algumas apreensões. 2014, 161 f. Dissertação (Mestrado em Educação Matemática) - Instituto de Geociências e Ciências Exatas, Universidade Estadual Paulista, Rio Claro, 2014.

ROMANOWSKI, Caroline Leonhardt. Indicadores das representações sociais da superdotação na discursividade das professoras. 2013, 92 f. Dissertação (Mestrado em Educação) -Universidade Federal de Santa Maria, Santa Maria, 2013.

RUNDBLAD, Emilia. Matematisk begåvning: Hur kan det mätas och vad karaktäriserar matematiskt begåvade elever?: En systematisk litteraturstudie för elever i lägre åldrar. 2014. 35 f. Student thesis - School of Science and Technology, Örebro University, Sweden, 2014.

Skolors arbete med matematiskt begåvade elever: en intervjustudie med fokus på rektorer för grundskolans tidiga åldrar. 2015. $41 \mathrm{f}$. Student thesis School of Science and Technology, Örebro University, Sweden, 2015. 
SANTOS, Amanda Oliveira dos. Diferentes olhares e o mesmo foco: as concepções dos professores e o comportamento de altas habilidades/superdotação. 2015 a, 142 f. Dissertação (Mestrado em Educação) Universidade Federal da Bahia, Salvador, 2015.

SANTOS, Lara Cristina Antunes dos. Superdotados acompanhados serviço especializado: características clínicas, sociodemográficas e qualidade de vida. 2015 b, 66 f. Dissertação (Mestrado em Saúde Coletiva) - Universidade Estadual Paulista Júlio de Mesquita Filho, Botucatu, 2015.

SANTOS, Janaina Teles Pereira. A gestão escolar na construção de uma escola inclusiva: fundamentos e práticas na rede de ensino municipal de São Luís/MA. 2016, 106 f. Dissertação (Mestrado em Educação) - Universidade Federal do Maranhão, São Luís, 2016.

SCHREIBER, Dayana Valéria Folster Antonio. Política educacional, trabalho docente e alunos da modalidade educação especial: um estudo nos anos iniciais do Ensino Fundamental. 2012, 204 f. Dissertação (Mestrado em Educação) Universidade Federal de Santa Catarina, Florianópolis, 2012.

SILVA, Elissandra Paraíso da. Um estudo sobre o atendimento educacional especializado para alunos com altas habilidades/superdotação na rede municipal de educação de Angra dos Reis/RJ. 2014a, 116 f. Dissertação (Mestrado em Educação, Contextos Contemporâneos e Demandas Populares) Universidade Federal do Rio de Janeiro, Rio de Janeiro, 2014.

SILVA, Josenildo Pereira da. Formação docente em tempos de educação inclusiva: cenários e desafios em uma escola pública. 2014b, 114 f. Dissertação (Mestrado em Educação) - Universidade Federal do Rio Grande do Norte, Natal, 2014.

SILVEIRA, Sheila Torma da. A aprendizagem de uma criança com Altas Habilidades/Superdotação e Transtorno de Asperger. 2014, 78 f. Dissertação (Mestrado em Educação) - Universidade Federal de Santa Maria, Santa Maria, 2014.

SOUZA, Alexandra da Costa. Características Desejáveis em Professores de Alunos com Altas Habilidades/Superdotação. 2010, 76 f. Dissertação (Mestrado em Educação) - Universidade Católica de Brasília, Brasília, 2010. alunos com altas habilidades/superdotação presentes na sala de recursos multifuncional, Tipo I. 2016. 223 f. Dissertação (Mestrado em Educação) Universidade Estadual do Centro-Oeste, Guarapuava, 2016. 
TAUCEI, Joulilda dos Reis. Dupla excepcionalidade e interação social: impasses e possibilidades. 2015, 214 f. Dissertação (Mestrado em Educação) - Universidade Federal do Paraná, Curitiba, 2015.

TRANCOSO, Bartira Santos. Percepções de alunos superdotados acerca das relações entre desenvolvimento socioemocional e desempenho acadêmico. 2011. 221 f. Dissertação (Mestrado em Educação) - Universidade Federal do Paraná, Curitiba, 2011.

TSUBOI, Maria da Penha Padilha. Um percurso nacional - 20 anos de estudos sobre altas habilidades/superdotação: a contribuição discente dos programas de Pós-Graduação. 2002. 218 f. Dissertação (Mestrado em Educação) - Universidade do Estado do Rio de Janeiro, Rio de Janeiro, 2002

VIANA, Tania Vicente. Avaliação educacional diagnóstica: uma proposta para identificar altas habilidades. 2005, 318 fl. Dissertação (Mestrado em Educação) Departamento de Educação da Universidade Federal do Ceará (UFC), Fortaleza, 2005.

VIANA, Jacilene Mesquita. Emoção, inteligência e aprendizagem: a busca de caminhos possíveis para o desenvolvimento de altas habilidades em sala de aula. 2003, 164 f. Dissertação (Mestrado em Educação) - Universidade do Estado do Rio de Janeiro, Rio de Janeiro, 2003.

VIEIRA, Nara Joyce Wellausen. Viagem a “Mojave - óki!": uma trajetória na identificação das altas habilidades/superdotação em crianças de quatro a seis anos. 2005. 228 f. Tese (Doutorado em Educação), Universidade Federal do Rio Grande do Sul, Porto Alegre, 2005.

VIRGOLIM, Angela Mágda Rodrigues. O indivíduo superdotado: história, concepção e identificação. Psicologia: Teoria e Pesquisa, v.13, 173183, 1997. 2005.

VIRGOLIM, Angela Mágda Rodrigues. Altas habilidades/superdotação: encorajando potenciais. Ministério da Educação - Secretaria de Educação Especial (MEC/SEESP), Brasília/DF, 2007.

VIRGOLIM, Angela Mágda Rodrigues. A contribuição dos instrumentos de investigação de Joseph Renzulli para a identificação de estudantes com altas habilidades/ superdotação. Revista Educação Especial, v. 27, n. 50, set./dez. 2010. 
ZAVITOSKI, P. Superdotação e criatividade: análise de dissertações e teses brasileiras. 2015. 66 f. Dissertação (Mestrado em Psicologia do desenvolvimento e aprendizagem) - Universidade Estadual Paulista Julio de Mesquita Filho, Bauru, 2015.

Recebido: 13 fev. 2019

Aprovado: 16 abr. 2020

DOI: $10.3895 /$ rbect.v13n2.9582

Como citar: RAMBO, M. C. D.; FERNANDES, S. H. A. A. Uma revisão bibliográfica sobre as altas

habilidades/superdotação com enfoque na matemática. Revista Brasileira de Ensino de Ciência e Tecnologia, Ponta Grossa, v.13, n. 2, p. 78-105, mai./ago. 2020. Disponível em:

$<$ https://periodicos.utfpr.edu.br/rbect/article/view/9582>. Acesso em: XXX

Correspondência: Michele Cristiane Diel Rambo - michele.rambo@ifto.edu.b

Direito autoral: Este artigo está licenciado sob os termos da Licença Creative Commons-Atribuição 4.0

Internacional. 